\title{
Plume and Shock Interaction Effects on Sonic Boom in the 1-foot by 1-foot Supersonic Wind Tunnel
}

\author{
Raymond Castner ${ }^{1}$, \\ NASA Glenn Research Center, Cleveland, Ohio, 44135 \\ Alaa Elmiligui ${ }^{2}$, \\ NASA Langley Research Center, Hampton, Virginia, 23681 \\ Susan Cliff ${ }^{3}$, \\ NASA Ames Research Center, Moffett Field, California, 94035 \\ Courtney Winski ${ }^{4}$, \\ NASA Langley Research Center, Hampton, Virginia, 23681
}

\begin{abstract}
The desire to reduce or eliminate the operational restrictions of supersonic aircraft over populated areas has led to extensive research at NASA. Restrictions are due to the disturbance of the sonic boom, caused by the coalescence of shock waves formed by the aircraft. A study has been performed focused on reducing the magnitude of the sonic boom $\mathrm{N}$-wave generated by airplane components with a focus on shock waves caused by the exhaust nozzle plume. Testing was completed in the 1 -foot by 1 -foot supersonic wind tunnel to study the effects of an exhaust nozzle plume and shock wave interaction. The plume and shock interaction study was developed to collect data for computational fluid dynamics (CFD) validation of a nozzle plume passing through the shock generated from the wing or tail of a supersonic vehicle. The wing or tail was simulated with a wedgeshaped shock generator. This test entry was the first of two phases to collect schlieren images and off-body static pressure profiles. Three wedge configurations were tested consisting of strut-mounted wedges of 2.5degrees and 5-degrees. Three propulsion configurations were tested simulating the propulsion pod and aft deck from a low boom vehicle concept, which also provided a trailing edge shock and plume interaction. Findings include how the interaction of the jet plume caused a thickening of the shock generated by the wedge (or aft deck) and demonstrate how the shock location moved with increasing nozzle pressure ratio.
\end{abstract}

\section{Nomenclature}

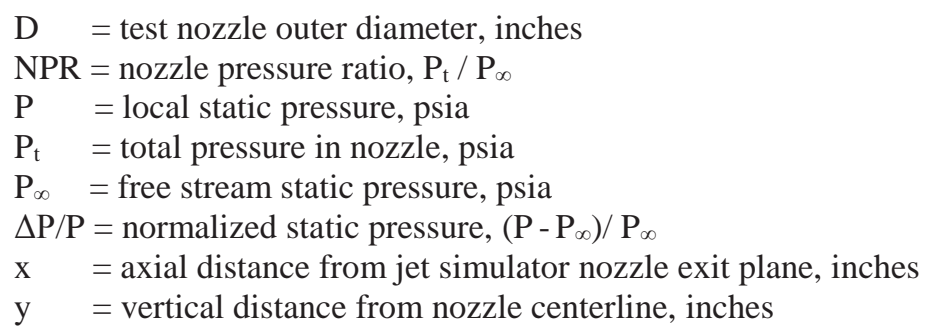

\footnotetext{
${ }^{1}$ Aerospace Engineer, Inlet and Nozzle Branch, 21000 Brookpark Road, AIAA Associate Fellow.

${ }^{2}$ Research Aerospace Engineer, Configurations Aerodynamics Branch, NASA Langley, AIAA Senior Member

${ }^{3}$ Aerospace Engineer, Applied Modeling and Simulations Branch, Moffett Field, AIAA Associate Fellow

${ }^{4}$ Research Aerospace Engineer, Configurations Aerodynamics Branch, NASA Langley, AIAA Member
} 


\section{Introduction}

NASA has been conducting extensive research to reduce the sonic boom signature caused by supersonic flight speeds. The High Speed Project, under NASA's Fundamental Aeronautics Program, has studied a number of technology challenges related to supersonic flight. These challenges include sonic boom, supersonic cruise efficiency, airport noise, high altitude emissions, lightweight engines/airframes, and multidisciplinary design. The present work is relevant to sonic boom reduction, which aims to mitigate the disturbance caused by the sonic boom and potentially remove the present aircraft operational restriction of supersonic flight over water only. A sonic boom is generated by coalescing shock waves and expansion fans formed by aircraft components, which generate an $\mathrm{N}$-wave. The $\mathrm{N}$-wave consists of a sharp rise in pressure versus time as the aircraft 'bow-wave' passes over an observer, followed by a rapid reduction in pressure dropping below atmospheric pressure, and finally a sharp return to atmospheric pressure.

Previous work by NASA, such as the Shaped Sonic Boom Demonstrator ${ }^{1}$ (SSBD), the Quiet Spike ${ }^{2}$, and the NASA N+2 vehicle studies ${ }^{3,4}$, studied how the sonic boom signatures can be reduced with aircraft shaping. Further work was desired to understand the contribution of the nozzle exhaust plume to the sonic boom signature from the aft portion of a supersonic vehicle. This could be accomplished through the study of how aft components, such as the tail, nacelles, and nozzles contributed to the right hand portion of the sonic boom $\mathrm{N}$-wave.

Early work on exhaust nozzle contribution to sonic boom included a report by Putnam and Capone ${ }^{5}$, and another by Barger and Melson ${ }^{6}$. In the work by Putnam and Capone, nozzles were tested that ranged from a fullyexpanded Mach 1.7 nozzle to a fully-expanded Mach 2.9 nozzle. Their study was conducted in a wind tunnel where near-field pressure measurements were made at one nozzle diameter away from the model. Wind tunnel conditions were Mach 2.2 at a simulated altitude of 50,000 feet. Computational fluid dynamics (CFD) analysis ${ }^{7}$ determined that over-expanded and under-expanded operation of a nozzle had an effect on the $\mathrm{N}$-wave boom signature. The work demonstrated the feasibility of reducing the magnitude of the sonic boom $\mathrm{N}$-wave by controlling the nozzle plume interaction with the nozzle boat-tail flow structure. Under-expanded exhaust nozzle flow had a favorable result on near field pressure signatures, suggesting that the nozzle plume shock location could be controlled through control of nozzle pressure or nozzle divergent section geometry.

The study of exhaust nozzle plume effect on sonic boom has progressed from analysis and testing of an isolated nozzle to slot nozzles ${ }^{8}$ and engine-wing-body models ${ }^{9,10}$. These studies also demonstrated how the nozzle lip shock from an under-expanded nozzle plume could suppress the nozzle boat-tail expansion and reduce the strength of the trailing shock.

Two recent CFD and experimental studies ${ }^{11,12}$ have studied the interaction of an exhaust nozzle plume and a shock wave generated by simple wedge-shaped shock generators. The shock location from the wedge moved upstream due to the interaction with the plume and the plume path was deflected by the pressure disturbance from the wedge. Movement of the shock location may impact the sonic boom signature for modern low boom supersonic transport configurations.

In 2009, the capability to test small-scale models in NASA GRC's 1-foot by 1-foot supersonic wind tunnel (1x1 SWT) was developed to validate CFDresults obtained for supersonic nozzle concepts. This capability was utilized for a fundamental study of nozzle plume and shock interaction effects summarized in this report. The present work studied the effects of a nozzle exhaust plume with a simulated tail shock. The tail shock was generated by two methods: (1) a simple wedge-shaped shock generator and (2) an aft deck from a simulated engine nacelle and vehicle. Near field pressure signatures were measured, which directly correlate to the sonic boom contribution of the nozzle and tail shock interaction. Wind tunnel test results include schlieren images of the nozzle exhaust shock structure and near-field static pressure profiles as collected from a static pressure probe. 


\section{Test Setup}

The small-scale wind tunnel model tested in the 1x1 SWT was designed to operate across a variety of wind tunnel Mach numbers, nozzle pressure ratios, and simulated altitudes. This section reviews the wind tunnel model, instrumentation, and location in the wind tunnel.

\section{II.a. Model}

The wind tunnel model consisted of three major parts: the upper plenum, the strut, and the lower plenum (as displayed in Fig. 1). A photo of the rig installation is provided in Fig. 2. The upper plenum design was 1-inch outer diameter, and had an overall length from the nosecone to the nozzle exit of 8.21 inches. Both nosecone and nozzle were attached with fine pitched threaded connections. The support strut was 0.35 inch in thickness and contained nine passages to supply airflow. Air supply lines were 0.25 inch diameter, and the passages supplied 90 psia of pressure to achieve 20 psia at the nozzle inlet for test conditions at 50,000 ft altitude. To accommodate larger nozzles and testing at lower altitudes, the maximum design pressure at the strut was 233 psia, to achieve 52 psia at the nozzle inlet. Choked orifice holes were needed on top of the strut supply lines to obtain required mass flow. Orifice holes were 0.210 inch diameter. Air was supplied to the bottom of the strut through a lower plenum by the centralized 450 psig pressurized air system at the NASA Glenn Research Center.

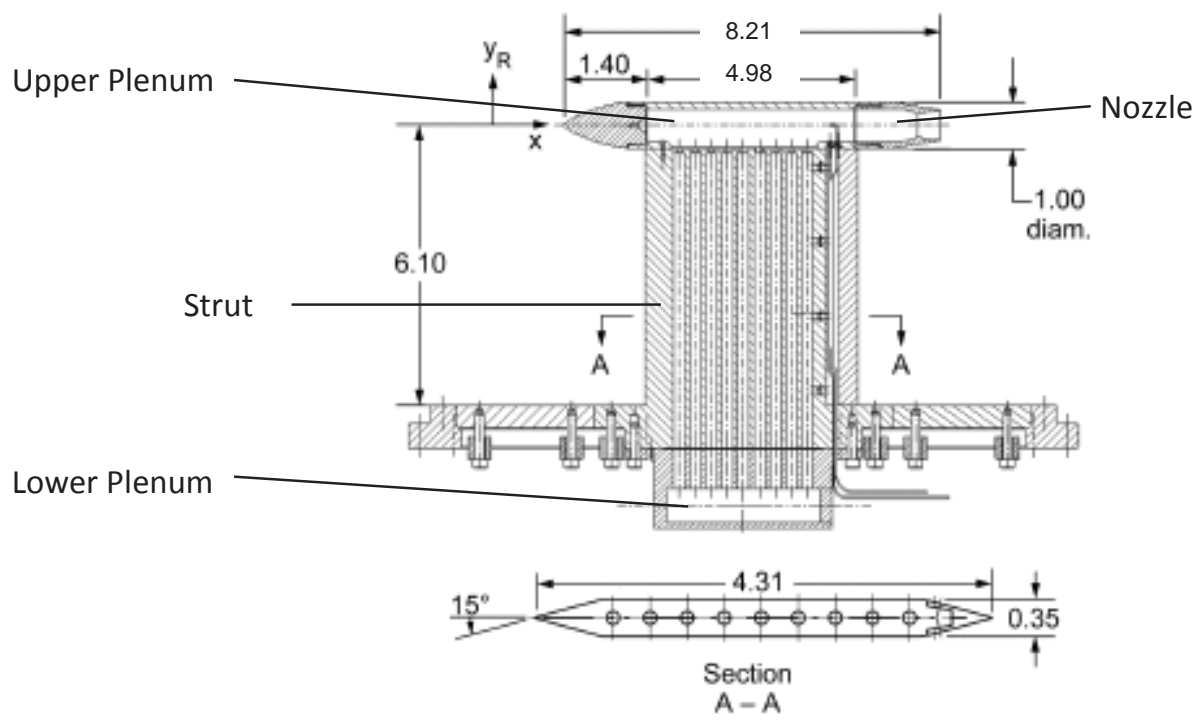

Figure 1. Wind Tunnel Model Cut-Away. Dimensions in inches. NASA Glenn Drawing G30008MRA100. 


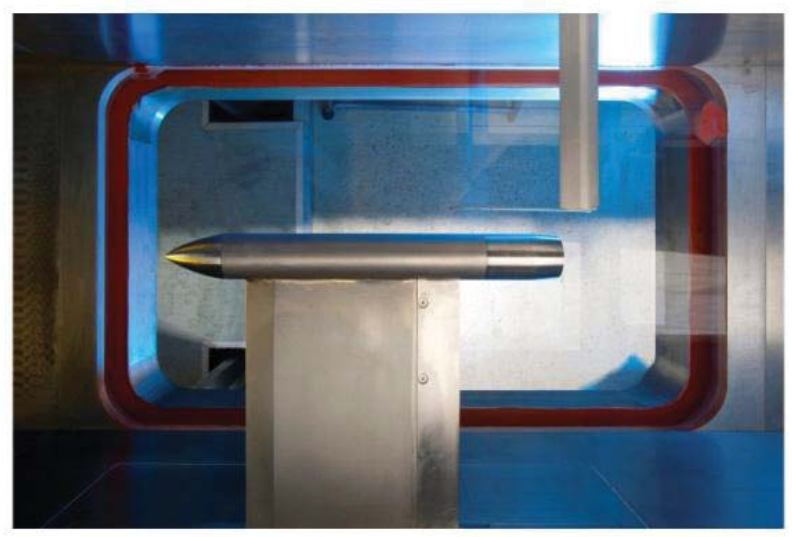

Figure 2. Wind Tunnel Model Photograph.

Downward view through the top schlieren window.

The location of the strut and model was designed to move forward and aft in the wind tunnel test section. This was accomplished with a slot, allowing six inches of overall travel. In this manner the rig location could be modified to avoid unforeseen wind tunnel flow effects or shock wave reflections. Manual changes to rig location could only be made between tests with the wind tunnel turned off.

\section{II.b. Instrumentation}

Nozzle pressure ratio (NPR) was determined based on mass flow measurement and nozzle throat diameter. Sonic flow equations for a venturi were used ${ }^{13}$ to perform this calculation. An external static pressure probe was designed to survey near-field static pressure profiles at one nozzle diameter above the rig centerline. The static pressure probe was mounted on an airfoil probe support and a sliding ball screw actuator from the opposite side of the tunnel. The probe passed through the tunnel sidewall and the actuator was installed in an enclosure to match the tunnel pressure. The overall assembly, showing the probe location, is provided in Fig. 3.

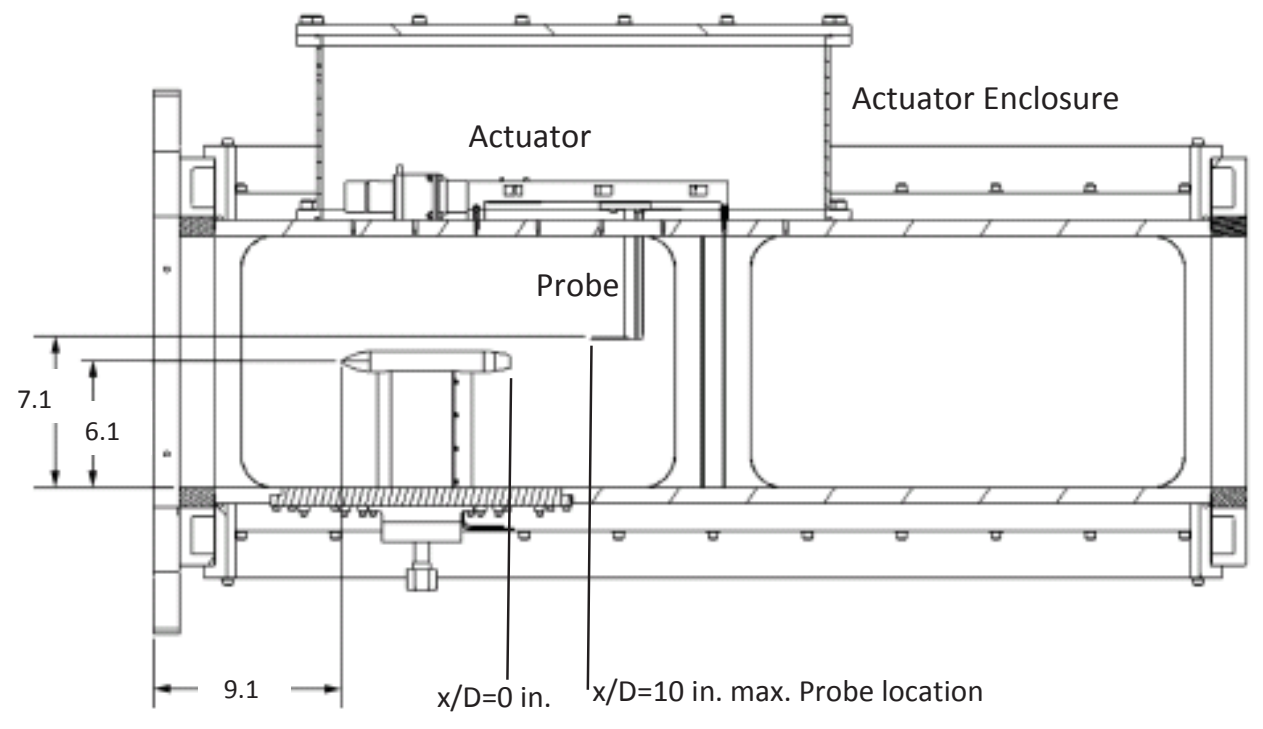

Figure 3. Wind Tunnel Model Cross Section as installed in the 1-foot by 1-foot SWT test section. Dimensions in inches. NASA Glenn drawing G30008MRA000. 
The static pressure probe had a capability to travel axially up to 8.0 inches to capture pressure profiles, with an $\mathrm{x} / \mathrm{D}=0$ chosen as the nozzle exit plane. The actuator position and probe starting location were changed during the test, dependent upon where the shock interaction was located. Two static pressure probes were built, a 10-degree cone probe and a design based on Pinckney ${ }^{14}$. The 10-degree cone probe design, in Fig. 4, had difficulty capturing shock waves. This difficulty was demonstrated by a rounding of the peaks where shock waves occurred, caused by the high cone angle and the long distance between the probe tip and the static pressure measurement ports where the measurement was not in the same flow environment as the probe tip. The Pinckney probe design had less sensitivity to angle of attack while achieving similar relaxation of static pressure at the location of the measurement ports. However, static pressure data collected with the Pinckney probe demonstrated a constant offset in $\Delta \mathrm{P} / \mathrm{P}$ of -0.8 when tested in an empty tunnel, suggesting that the Pinckney probe has an offset in the $\Delta \mathrm{P} / \mathrm{P}$ measurement. These probes were mounted on a 3/8 inch thick airfoil strut, allowing 5.625 inches of probe length between the static pressure holes and the airfoil support. For all experimental results presented, the Pinckney probe was used with a 0.5 psi differential pressure transducer referenced to the test section static pressure. The accuracy of this measurement was $+/-0.1$ percent of full scale.
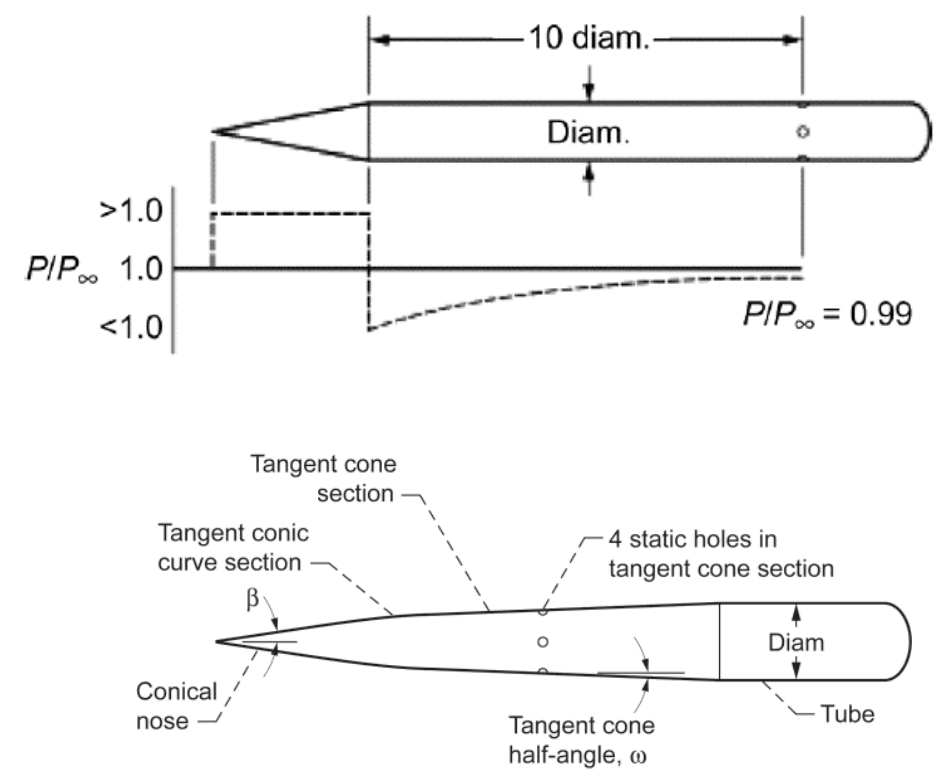

Figure 4. 10-degree cone probe and Pinckney probe design $(\beta=10 ; \omega=1.5)$.

The model was placed between two transparent sidewalls in the 1-foot by 1-foot SWT for schlieren photography.

\section{II.c. Model Location}

The location of the model in the wind tunnel was a concern. Correct model location was necessary to provide a clean nozzle flow-field at the correct Mach number. The nozzle flow-field also had to be free of shock reflections and shock interactions. A schlieren image, Fig. 5, was collected with the nozzle operating at an NPR of 8. Six sources of shock waves were evident. It was a challenge to place the nozzle inside these shocks and provide a clean nozzle flow-field. Sources for shock waves in the tunnel were:

1. Wind tunnel nozzle.

2. Nosecone tip.

3. Nosecone and strut intersection. 
4. Tunnel wall reflections.

5. Strut leading edge.

6. Nozzle plume (shock of interest).

The shock wave from the wind tunnel nozzle block was generated by a small step in the tunnel wall. This step was located at the end of the interchangeable wind tunnel throat block, upstream of the model. Through careful model placement, the shock wave from the nosecone tip was co-located with the wind tunnel nozzle block shock. Shock waves from the nosecone and strut interaction were set by the strut geometry. This model design was kept as short as possible to avoid the wind tunnel wall reflections. The strut leading edge shock wave was a lateral shock wave that impacted the wind tunnel walls in a plane that appeared to interfere with the nozzle exhaust. However, the placement of this shock interaction was on the wind tunnel wall, six inches away from the nozzle plume. This interaction location was validated by pre-test calculations and flow visualization. Similarly, the strut trailing edge shock and expansion did not interfere with the nozzle plume. Finally, the nozzle plume shock structure is visible, which was the objective of the experiment.

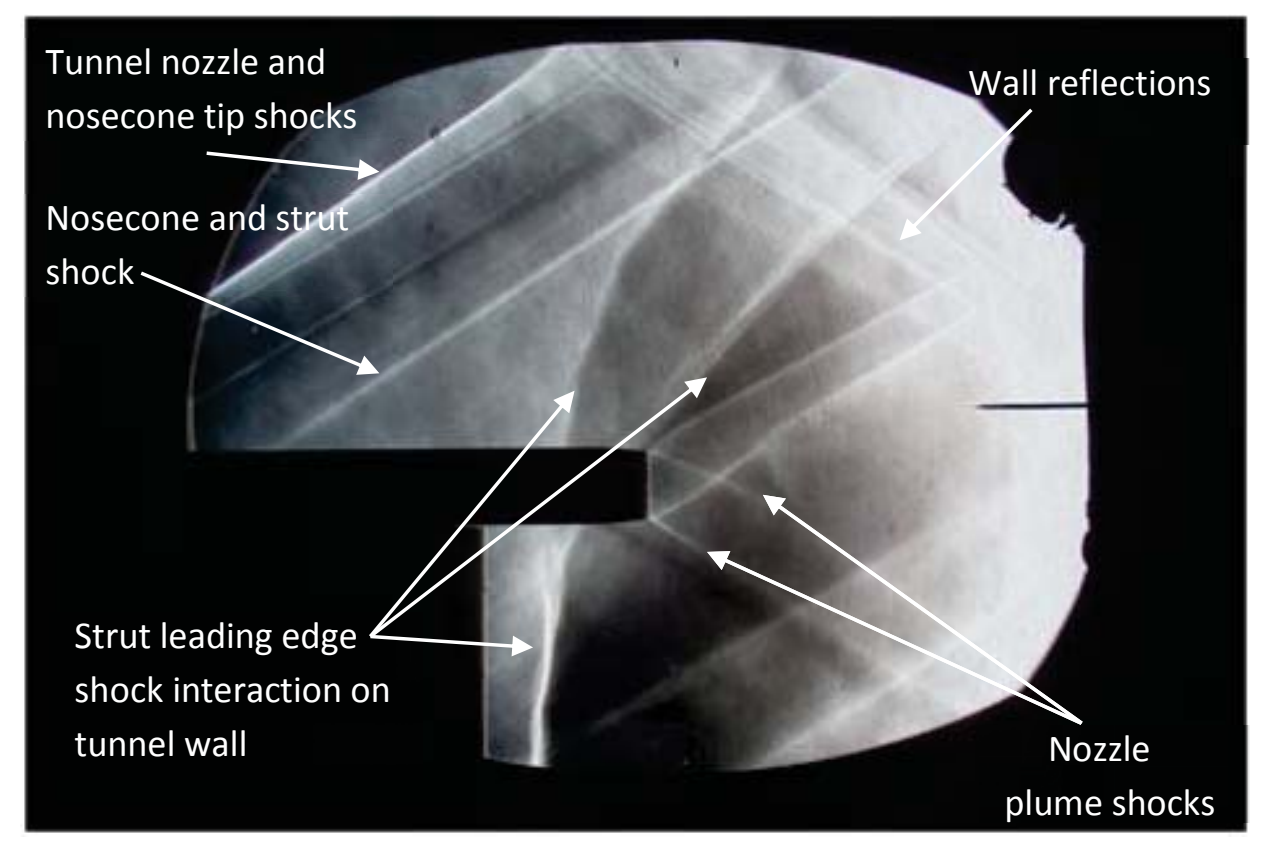

Figure 5. Schlieren image of tunnel shock structure.

To determine the interaction of the model strut shock wave with the wind tunnel glass sidewall, flow visualization was performed with a fluorescent paint and oil mixture. Results indicated clean flow at the nozzle location ${ }^{7}$.

\section{II.d. Nozzle}

The test nozzle was based on 'Nozzle 6' from Putnam and Capone. The nozzle was scaled to a 1 inch outer diameter, and was designed to be threaded onto the small jet rig (Fig. 3) for the 1x1 SWT. The design nozzle pressure ratio was 8.12 with a fully expanded jet Mach number of 2.024; the boat-tail angle was 5-degrees. The nozzle is shown in Fig. 6. 


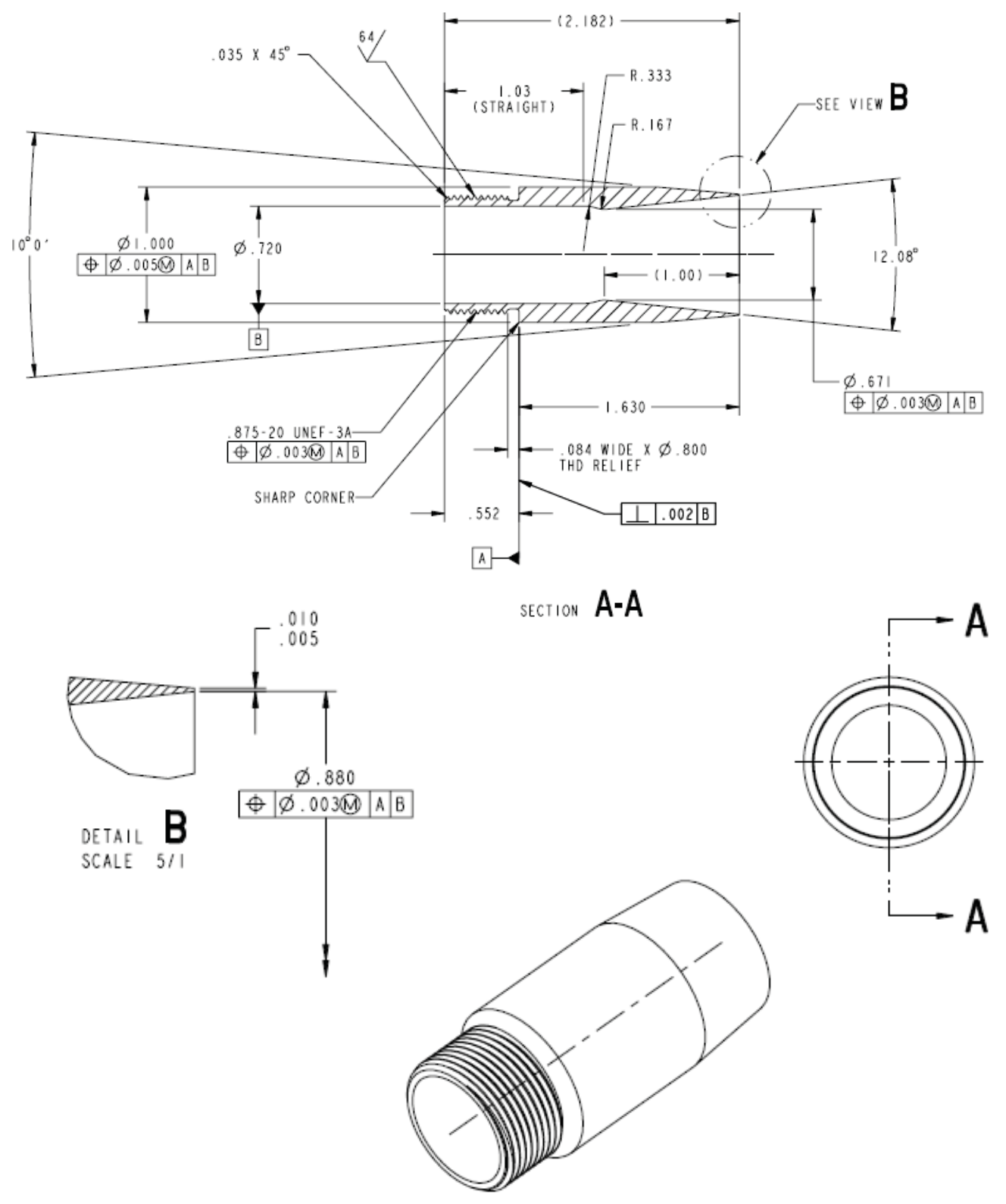

Figure. 6. "Nozzle 6” test nozzle. NASA Glenn Drawing G30008MRA125.

II.e. Wedge geometry

Three shock generator wedges were fabricated from 17-4 stainless steel to provide both a leading edge and trailing edge shock that would intersect with the nozzle plume. One wedge was built with a 5-degree wedge angle (10-degree inclusive), a second wedge was built with a 2.5-degree wedge angle (5-degree inclusive, see Fig. 7). These two wedges were 6 inches in overall chord, 8 inches in span, and were mounted on a diamond shaped support strut 4 inches high from the wind tunnel wall; the leading edge of the wedge was $0.37 \mathrm{in}$. downstream of the nozzle 
exit plane. The third wedge was 1.5 inch in overall chord, 3.5 inches in span, and was also mounted on a diamond shaped support strut 4 inches from the wall; the leading edge of the wedge was 0.385 in. upstream of the nozzle exit plane. The wedges possessed sharp leading and trailing edges with a maximum radius of 0.005 in.
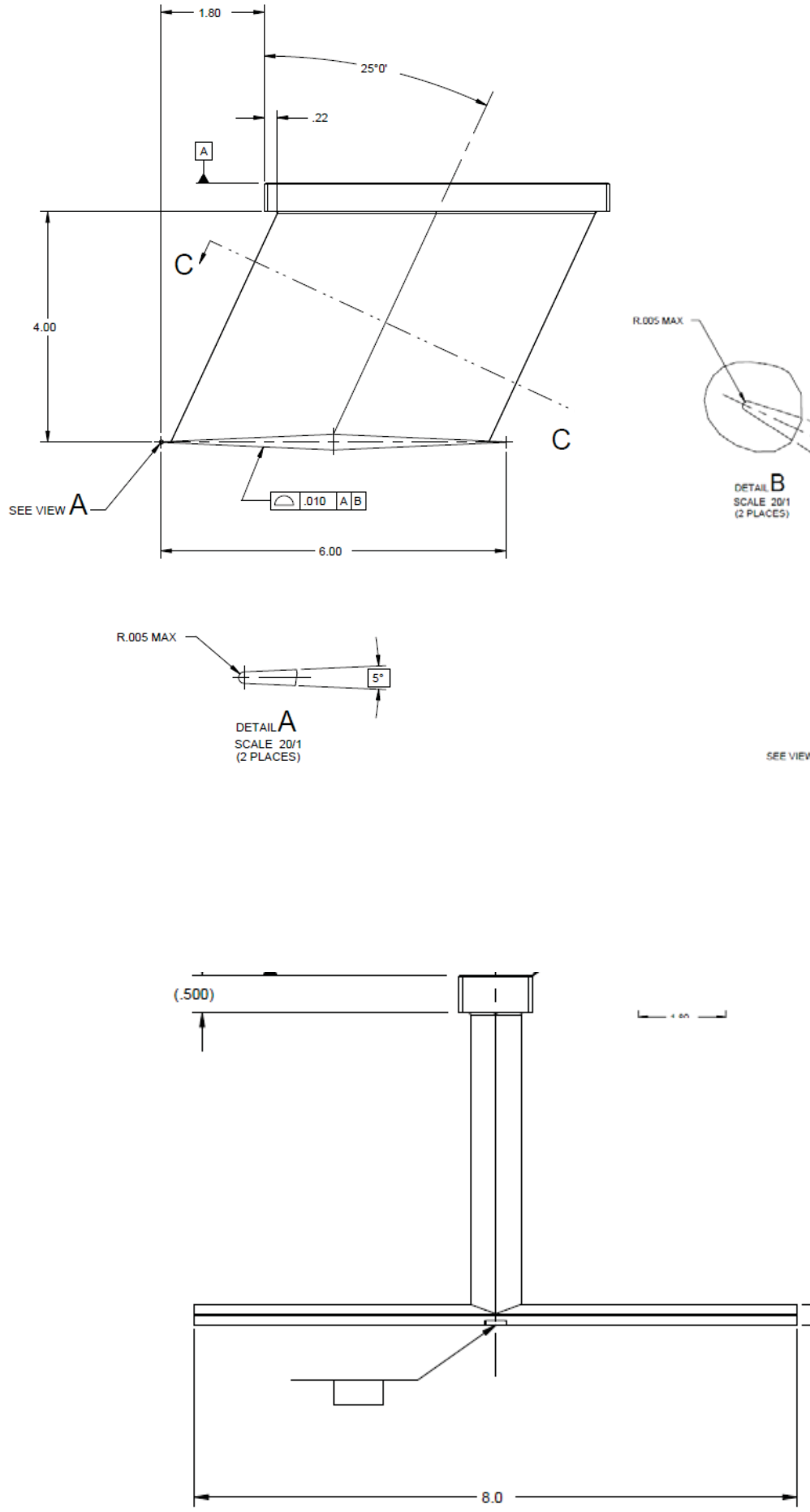

Figure 7. Shock Generator (2.5-degree is shown).

NASA Glenn drawing 130303MRA024. 
II.e. Nacelle and Aft Deck Geometry

Three nacelle shapes were fabricated using acrylonitrile butadiene styrene (ABS) material and three dimensional printing technology; the shapes were designed to fit over the existing 1 in. diameter upper plenum and nozzle. These nacelle shapes were designed to simulate the outer mold line of a notional propulsion pod. In many of the vehicle design concepts for a low sonic boom aircraft, the propulsion pod would be mounted on the top of the fuselage, utilizing an aft deck for sonic boom and noise shielding. Three aft deck lengths were studied: (1) the trailing edge of the aft deck was co-planar with the nozzle exit $(\mathrm{x} / \mathrm{D}=0),(2)$ the deck extended past the nozzle for a distance of 0.5 nozzle diameter $(\mathrm{x} / \mathrm{D}=0.5)$ and $(3)$ the deck extended past the nozzle exit for a distance of 1.0 nozzle diameter (x/D=1.0), see Fig. 8.

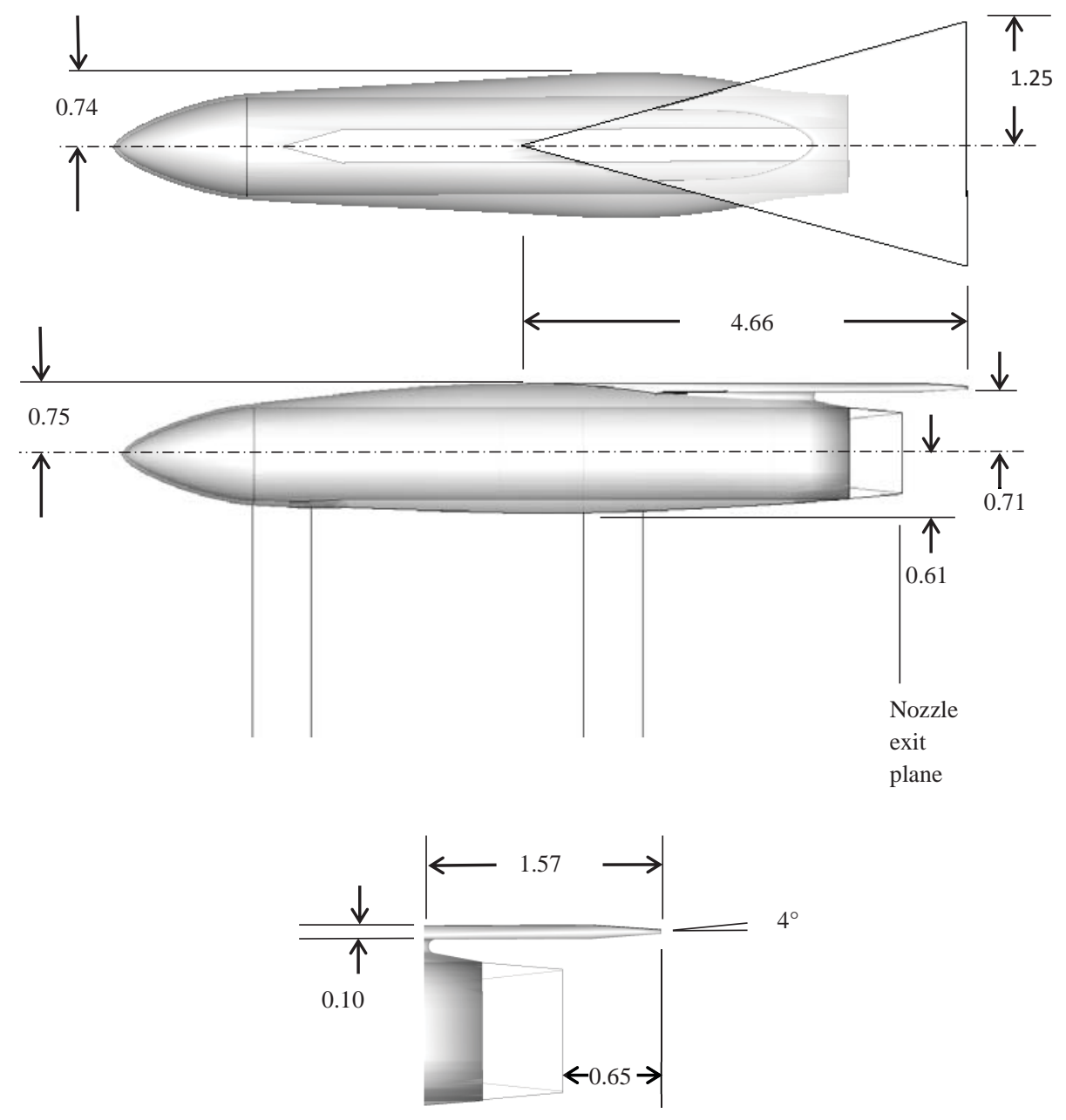

Figure 8. Nacelle and Aft Deck (x/D=1.0). 
III.a. Experimental Results

\section{Results}

In the 1x1 SWT, the experimental pressure signatures were measured at one-diameter away from the nozzle centerline, collected on the side opposite the model support strut. Data were collected at this location due to space restrictions in a small wind tunnel, and is consistent with previous experiments ${ }^{9}$. Experimental pressure signatures $(\Delta \mathrm{P} / \mathrm{P})$ were collected at 0.1 inch (sometimes 0.05 inch) increments.

\section{III.b. 5-Degree Shock Generator with 6 in. Chord}

The 5-degree shock generator was tested with and without 'Nozzle 6' at Mach 1.96. Both schlieren and static pressure profile data were collected. Fig. 9 shows the schlieren images for the wedge only (Fig. 9a) and for the wedge with 'Nozzle 6' (Fig. 9b) at NPR=12. The static pressure profiles as collected at one diameter below the nozzle centerline are plotted below the schlieren image. Before the location $\mathrm{x} / \mathrm{D}=3$ the static pressure profile exhibits the secondary shock from the exhaust nozzle plume barrel shock (or first shock diamond); the location of this shock moves downstream with increasing NPR. The leading edge shock from the shock generator was observed at $\mathrm{x} / \mathrm{D}=4$; the location of this shock also moves downstream with increasing NPR. When a comparison was made between the wedge only data and the combined nozzle with wedge data, the leading edge shock location occurs earlier than when the nozzle was not present (for NPR less than 14). This effect was due to the thickening of the shock wave and the interaction with the nozzle plume, and movement of the shock with decreasing nozzle pressure ratio. Finally, at $\mathrm{x} / \mathrm{D}=6.5$ the shock reflection from the wind tunnel model caused an increase in $\Delta \mathrm{P} / \mathrm{P}$ that was not present with the wedge only. Data was not collected downstream of $\mathrm{x} / \mathrm{D}=10$ due to contamination of the wedge shock signature due to the crossings of the reflected shock waves from the tunnel walls. The wedge trailing shock was not captured in this experiment due to this issue.

(a)

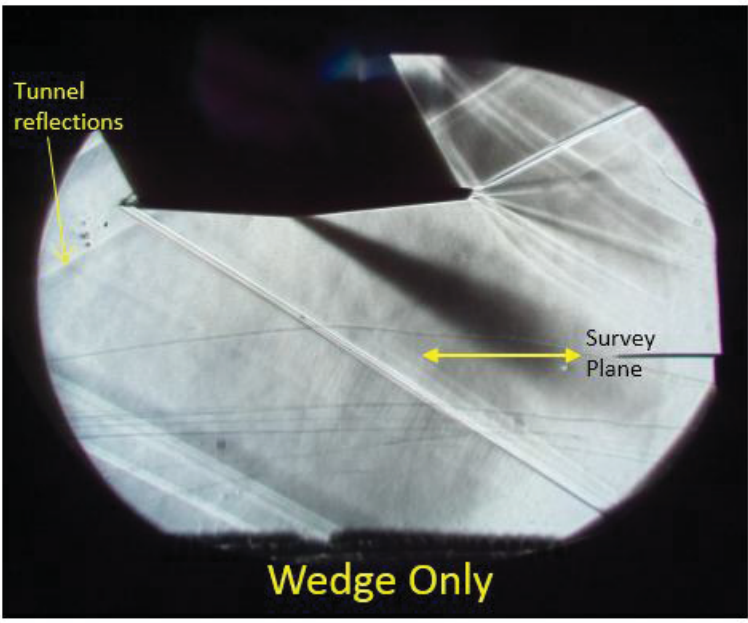

Aft shock movement with increasing NPR (b)
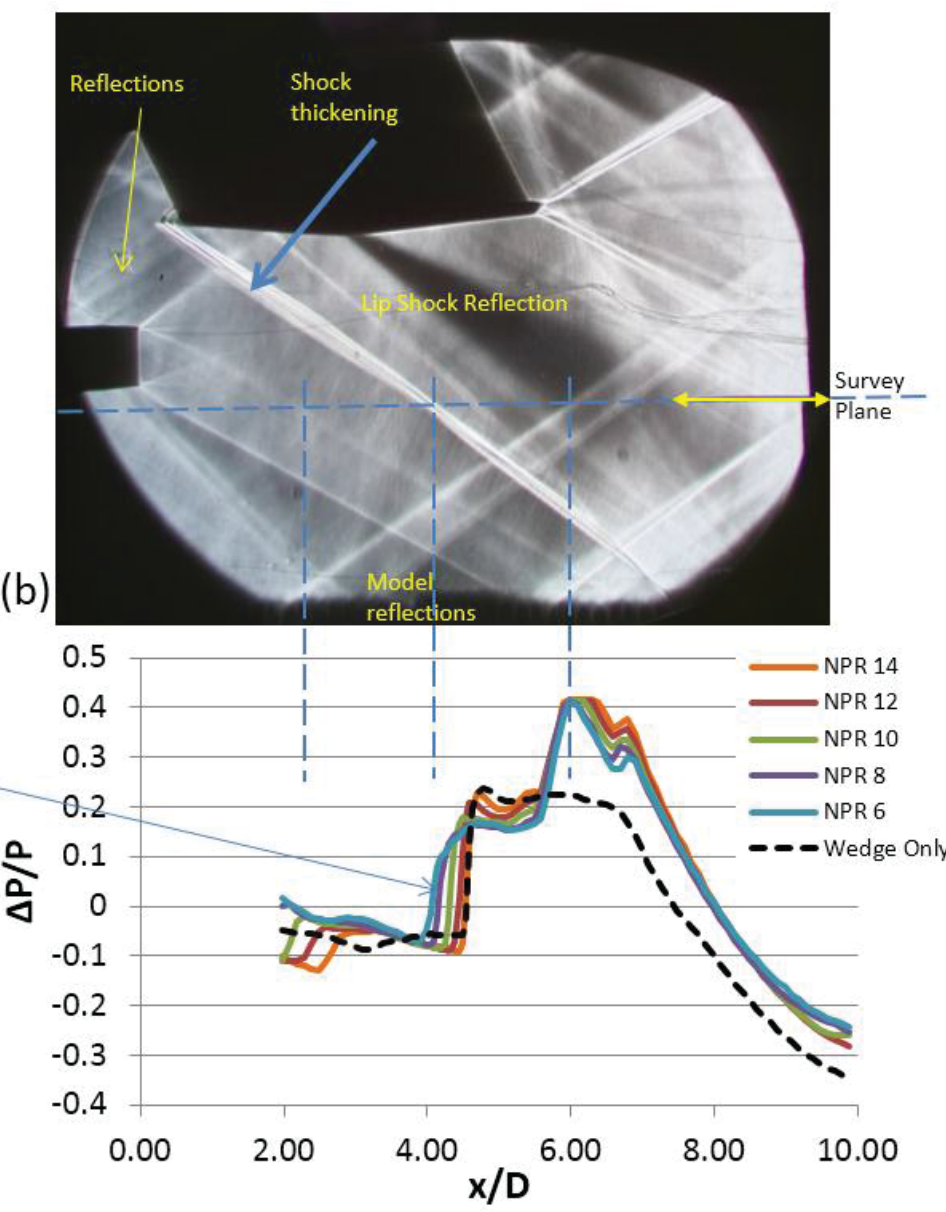

Figure 9. Schlieren images and static pressure profiles for the 5-degree wedge with 6 in. chord. 


\section{III.c. 2.5-Degree Shock Generator with 6 in. Chord}

The 2.5-degree shock generator was tested with and without 'Nozzle 6' at Mach 1.96. Both schlieren and static pressure profile data were collected. Fig. 10 shows the schlieren images for the wedge only (Fig. 10a) and for the wedge with 'Nozzle 6' (Fig. 10b) at NPR=12. The data was similar to the 5-degree wedge case. The static pressure profiles as collected at one diameter below the nozzle centerline are displayed below the schlieren image. Before $\mathrm{x} / \mathrm{D}=3$ the static pressure profile exhibits the secondary shock from the exhaust nozzle plume barrel shock (or first shock diamond); the location of this shock moves downstream with increasing NPR. The leading edge shock from the shock generator was observed at $\mathrm{x} / \mathrm{D}=4$; the location of this shock also moves downstream with increasing NPR. The leading edge shock location occurs earlier than when the nozzle was not present (wedge only) for NPR less than 14; this was due to the thickening of the shock wave due to the interaction with the nozzle plume, and movement of the shock with decreasing nozzle pressure ratio. Again, at $\mathrm{x} / \mathrm{D}=6.5$ the shock reflection from the wind tunnel model caused an increase in $\Delta \mathrm{P} / \mathrm{P}$ that was not present with the wedge only.
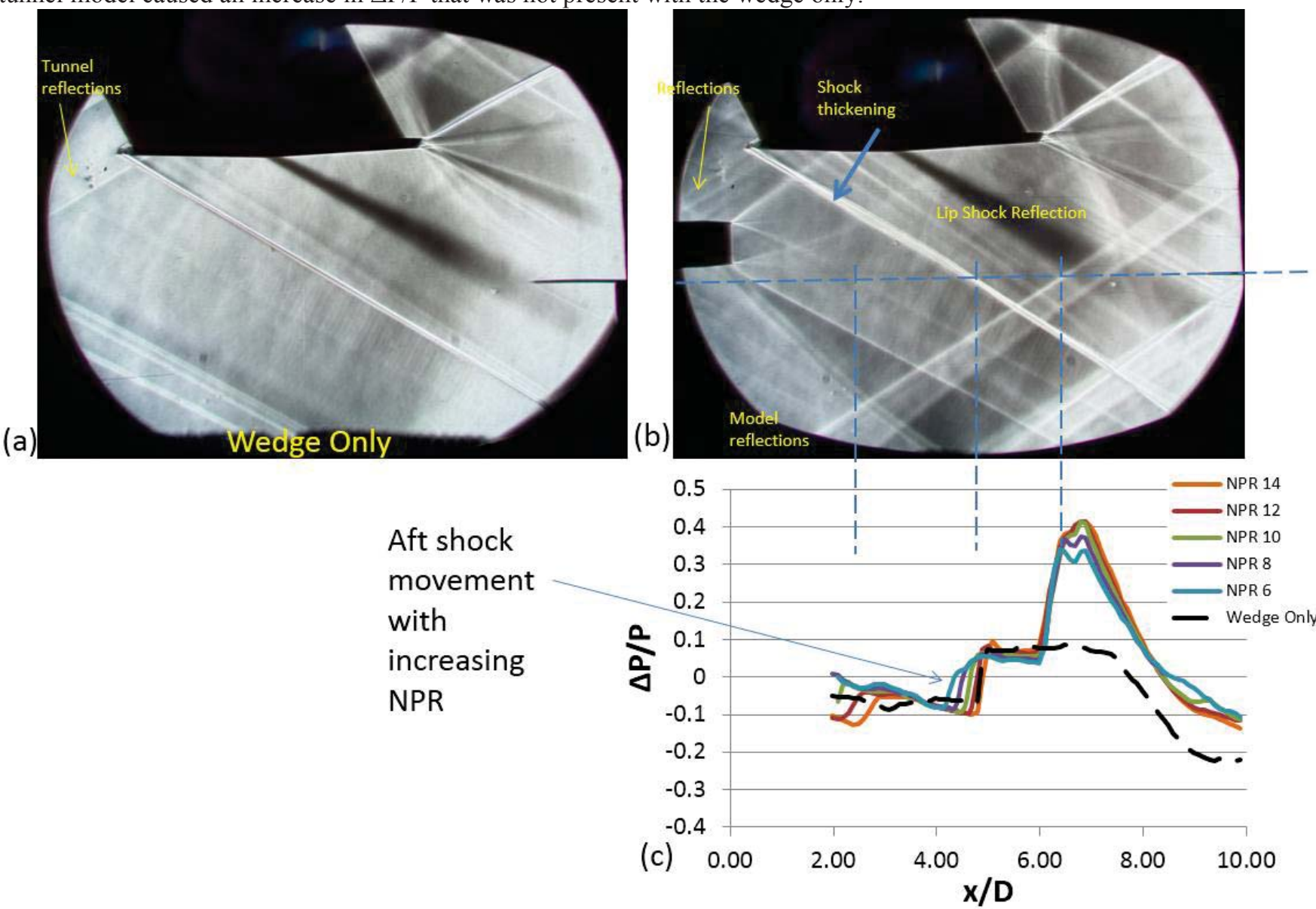

Figure 10. Schlieren images and static pressure profiles for the 2.5-degree wedge with 6 in chord. 


\section{III.d. 5-Degree Shock Generator with 1.5 in. Chord}

The 5-degree shock generator was tested with 'Nozzle 6' at Mach 1.96. Both schlieren and static pressure profile data were collected. Fig. 11 shows the schlieren image (NPR=12) for the wedge with 'Nozzle 6' at NPR=12. The static pressure profiles as collected at one diameter below the nozzle centerline are displayed below the schlieren image. This configuration was built to obtain both the leading and trailing wedge shock in the static pressure profile data. Before $\mathrm{x} / \mathrm{D}=2$, the static pressure profile exhibits the secondary shock from the exhaust nozzle plume barrel shock (or first shock diamond); the location of this shock moves downstream with increasing NPR. The leading edge shock from the shock generator was observed at $\mathrm{x} / \mathrm{D}=3$; the location of this shock also moves downstream with increasing NPR. At $x / D=7$ the shock reflection from the wind tunnel model caused an increase in $\Delta \mathrm{P} / \mathrm{P}$ that was not present with the wedge only. The trailing shock also moved downstream with NPR, but with reduced distance.

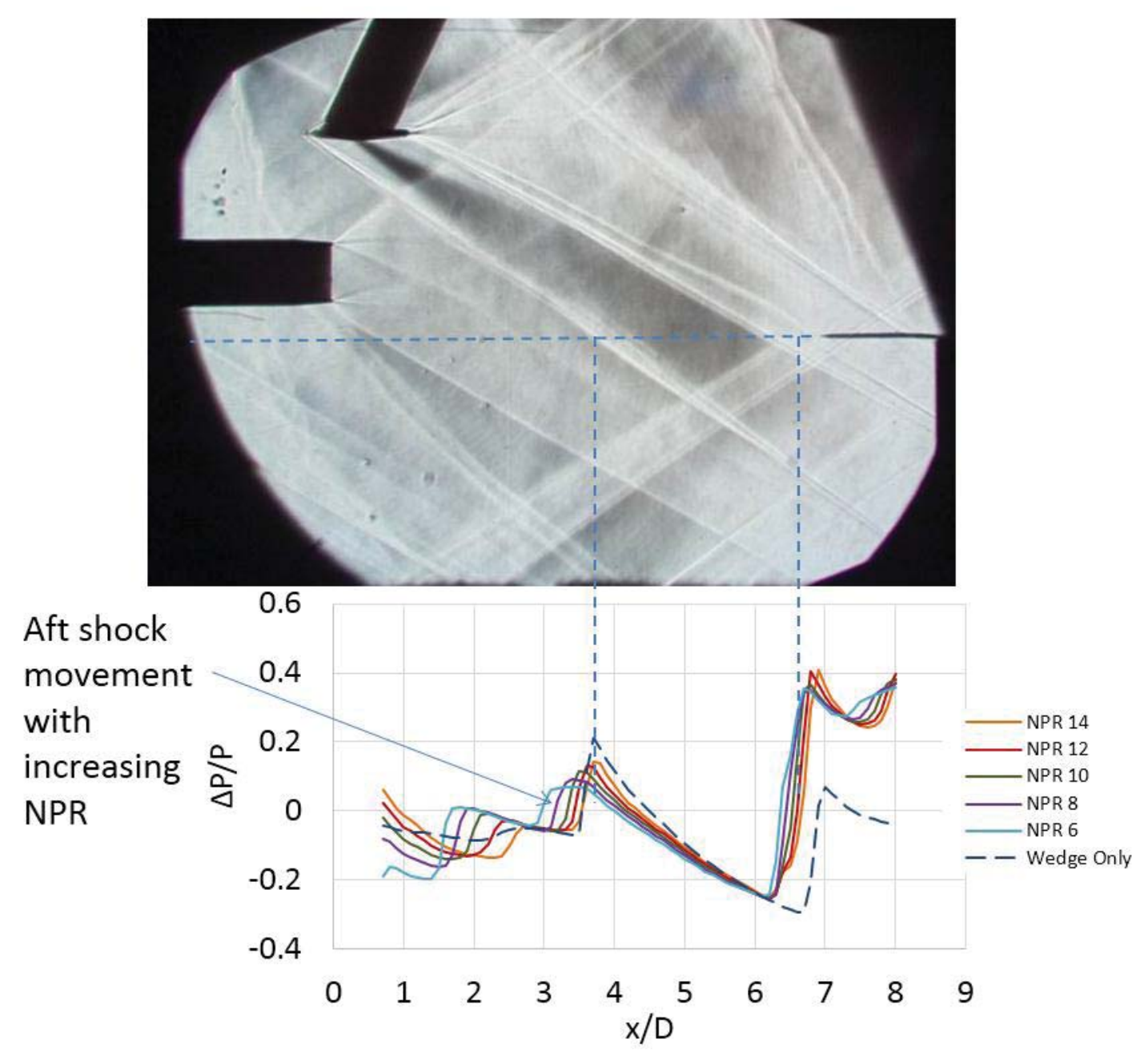

Figure 11. Schlieren images and static pressure profiles for the 5-degree wedge with $1.5 \mathrm{in}$. chord. 
III.e. Aft Deck x/D=0

The asymmetric nacelle with an aft deck $(\mathrm{x} / \mathrm{D}=0)$ was tested with 'Nozzle 6' at Mach 1.96. Both schlieren and static pressure profile data were collected. Fig. 12 shows the schlieren image (NPR=12) and the static pressure profiles collected at one diameter below the nozzle centerline. The probe actuator was relocated to capture the shock from the aft deck; probe surveys start at $x / D=-1.0$. The shock at $x / D=0$ is the expansion off of the trailing edge of the deck, and is the same location for all NPR's tested. At $\mathrm{x} / \mathrm{D}=0.5$ the data shows a difference in the deck trailing edge shock location as NPR is increased from NPR $=6$ to $N P R=14$, the shock moves upstream with increasing NPR. Before $\mathrm{x} / \mathrm{D}=2$ the static pressure profile exhibits the secondary shock from the exhaust nozzle plume barrel shock (or first shock diamond); the location of this shock moves downstream with increasing NPR, and is consistent with previous experimental results (nozzle only and data with the 5-degree and 2.5-degree wedge). Data was not collected downstream of $\mathrm{x} / \mathrm{D}=5.5$ due to limited actuator travel in this configuration, and due to the approaching contamination of the wedge shock signature due to the crossings of the reflected shock waves from the tunnel walls.

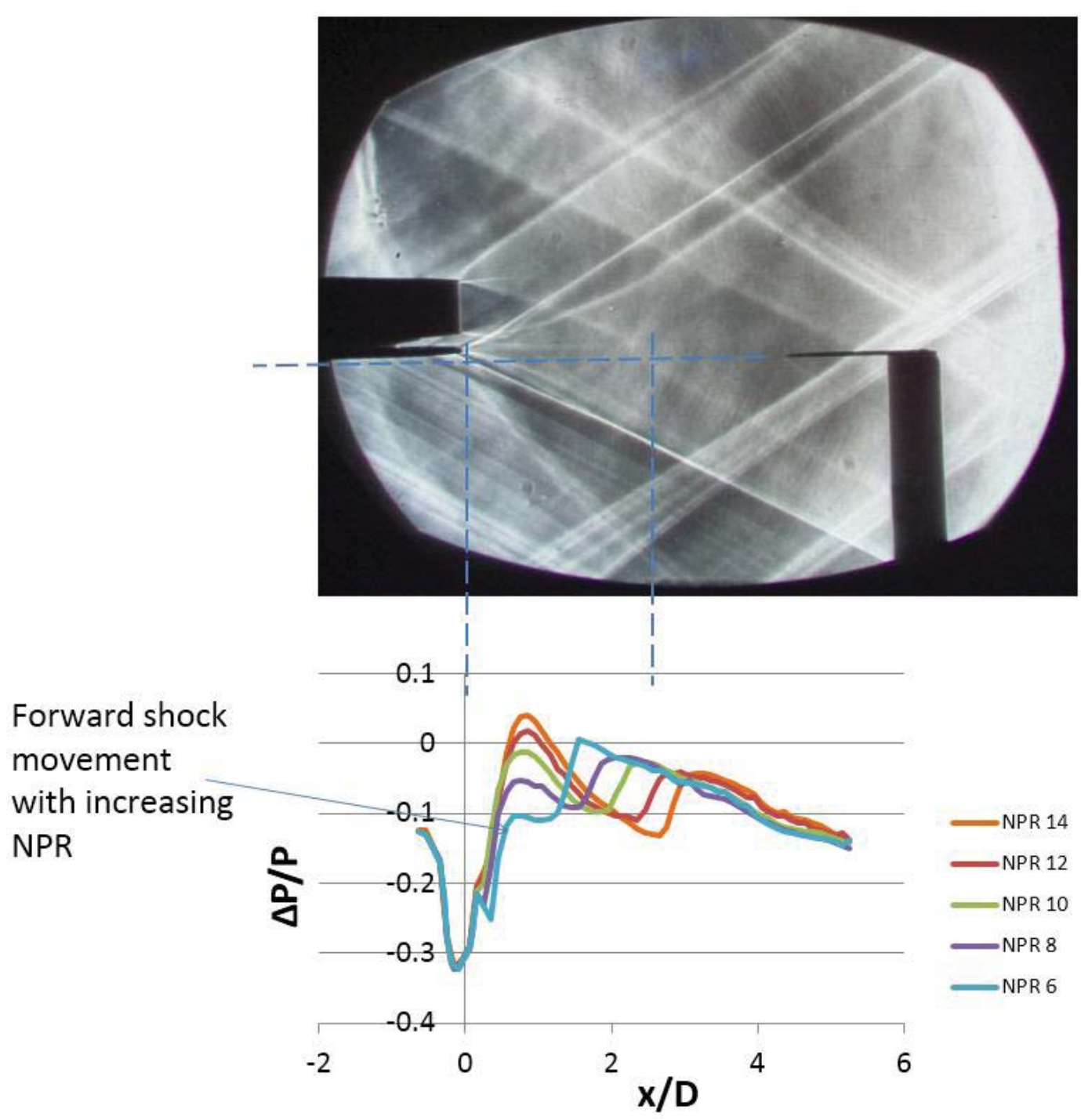

Figure 12. Schlieren image and static pressure profiles for the aft deck with $\mathrm{x} / \mathrm{D}=0$. 


\section{III.f. Aft Deck x/D=0.5}

The asymmetric nacelle with an aft deck $(\mathrm{x} / \mathrm{D}=0.5)$ was tested with 'Nozzle 6' at Mach 1.96. Both schlieren and static pressure profile data were collected. Fig. 13 shows the schlieren image (NPR=12) and the static pressure profiles as collected at one diameter below the nozzle centerline, displayed below the schlieren image. The shock at an $\mathrm{x} / \mathrm{D}=0.5$ is the expansion off of the trailing edge of the deck, and is the same location for all NPR's tested. At $\mathrm{x} / \mathrm{D}=1$ the data shows a difference in the deck trailing edge shock location as NPR is increased from $N P R=6$ to $N P R=14$, the shock moves upstream with increasing NPR. Before $x / D=2$ the static pressure profile again exhibits the secondary shock from the exhaust nozzle plume barrel shock.

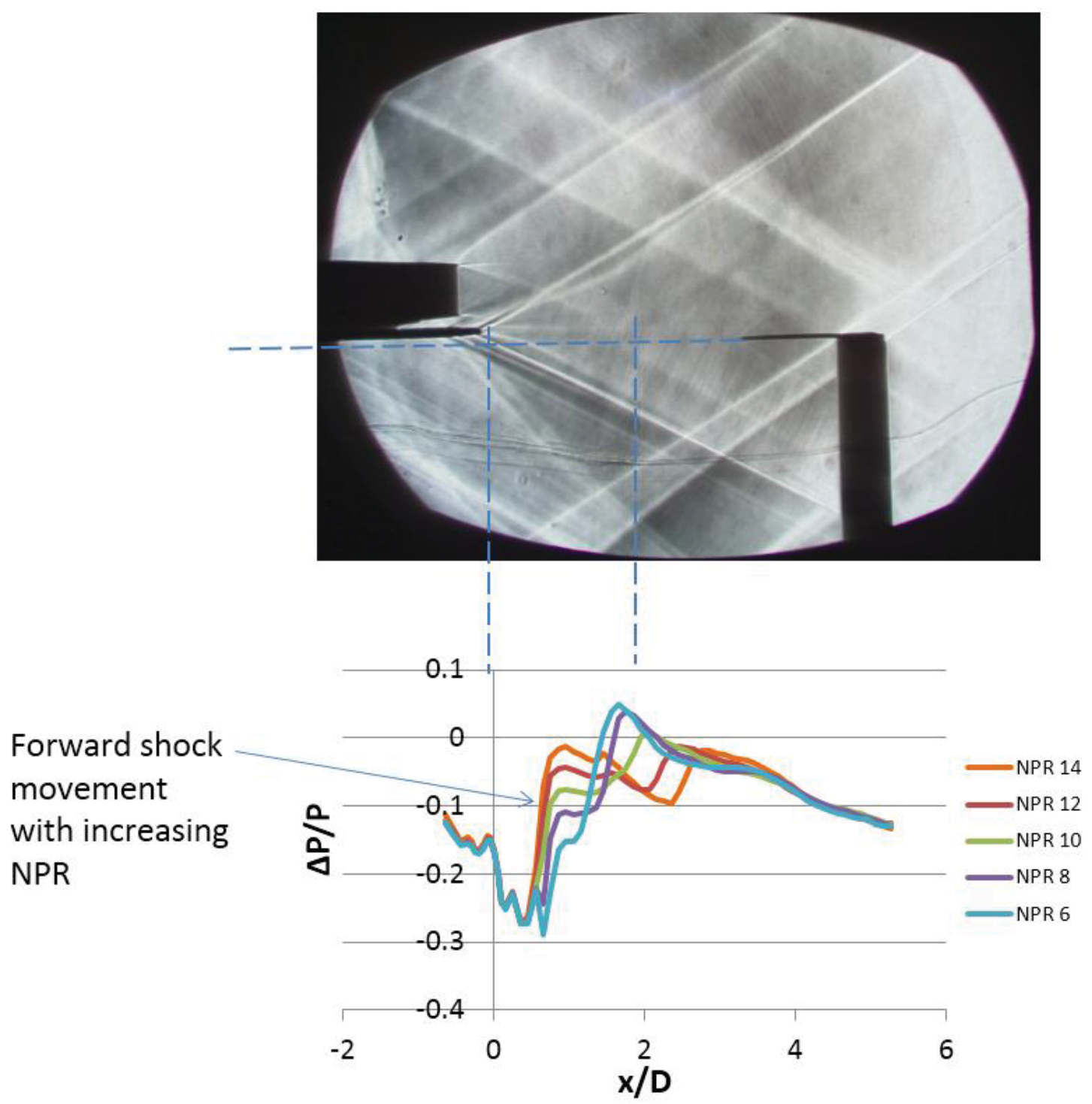

Figure 13. Schlieren image and lower static pressure profiles for the aft deck with $\mathrm{x} / \mathrm{D}=0.5$. 
Fig. 14 shows the schlieren image (NPR=12) and the static pressure profiles as collected at one diameter above the nozzle centerline(data at this location was not collected for the previous $\mathrm{x} / \mathrm{D}=0$ configuration). The shock at an $\mathrm{x} / \mathrm{D}=0.5$ is the lip shock, and moves upstream as NPR is increased. At $\mathrm{x} / \mathrm{D}>2$ the data shows a difference in the deck trailing edge shock location as NPR is increased from NPR=6 to NPR=14, the shock moves downstream with increasing NPR.

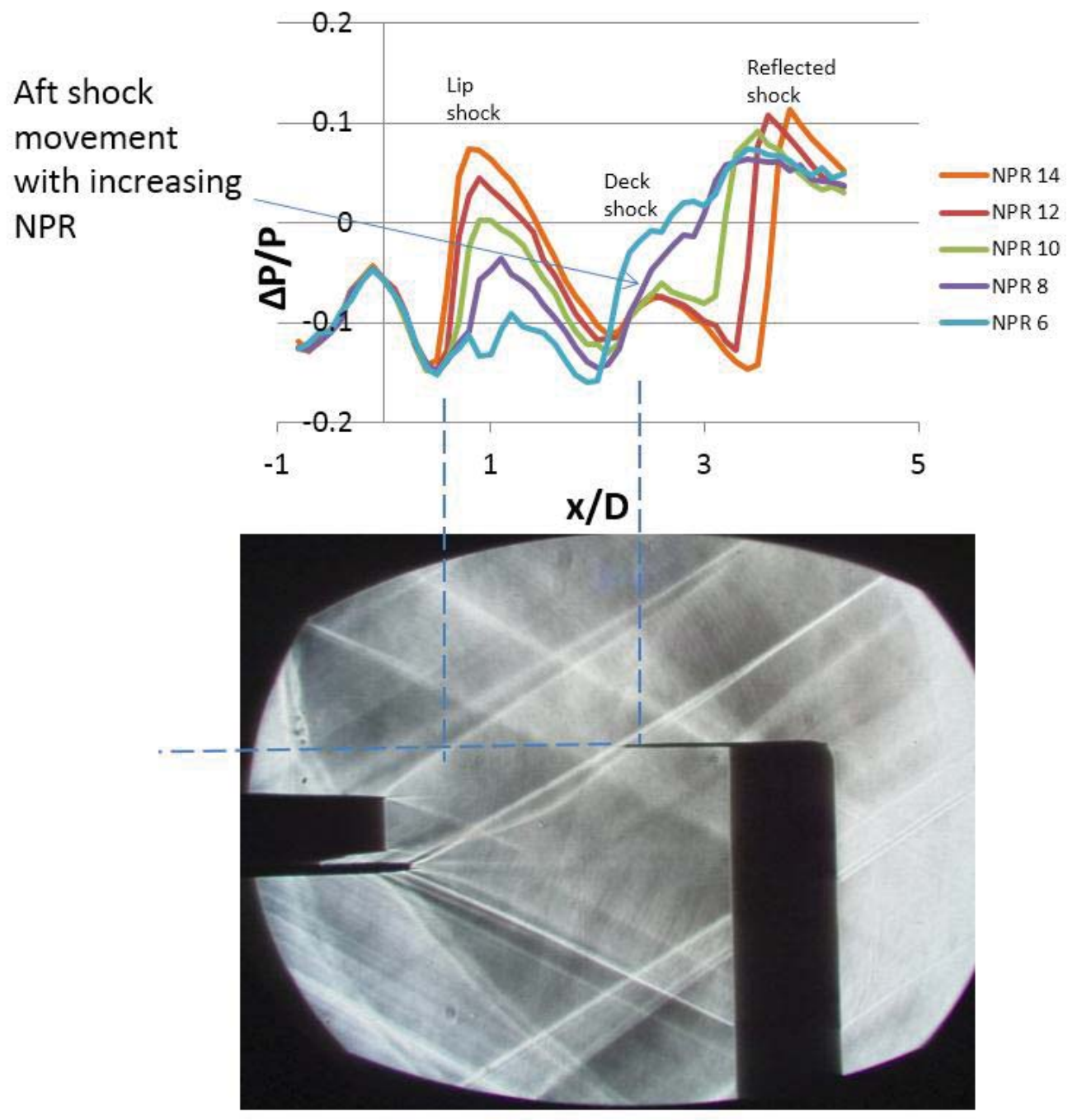

Figure 14. Schlieren image and upper static pressure profiles for the aft deck with $\mathrm{x} / \mathrm{D}=0.5$. 
A comparison was made between the schlieren images taken for this configuration at an NPR of 14 and an NPR of 6. Lines were superimposed on the shock waves generated above and below the deck at an NPR of 14 . These lines were then overlaid on the photograph from an NPR of 6 . In this manner, the movement of the shock waves from the aft deck could be visualized.

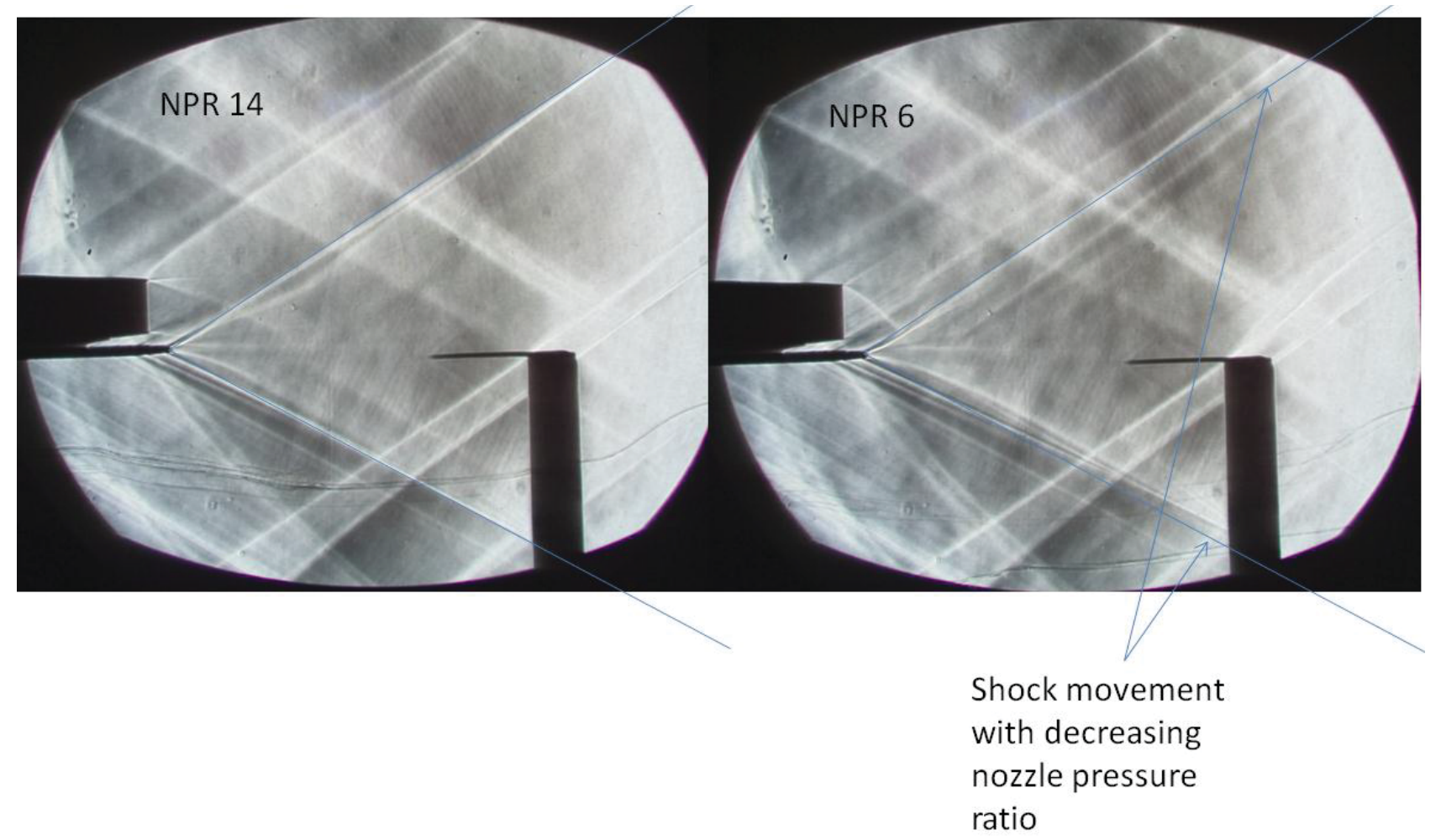

Figure 15. Comparison of NPR=6 and NPR=14 for aft deck configuration $\mathrm{x} / \mathrm{D}=0.5$. 
III.g. Aft Deck x/D=1.0

Fig. 16 shows the schlieren image and the static pressure profiles as collected at one diameter below the nozzle centerline, displayed below the schlieren image (NPR=12). The shock at an $\mathrm{x} / \mathrm{D}=0.5$ is the expansion off of the trailing edge of the deck, and is the same location for all NPR's tested. At $x / D=1$ the data shows a difference in the deck trailing edge shock location as NPR is increased from NPR $=6$ to NPR=14, the shock moves upstream with increasing NPR. Before $\mathrm{x} / \mathrm{D}=2$ the static pressure profile again exhibits the secondary shock from the exhaust nozzle plume barrel shock.

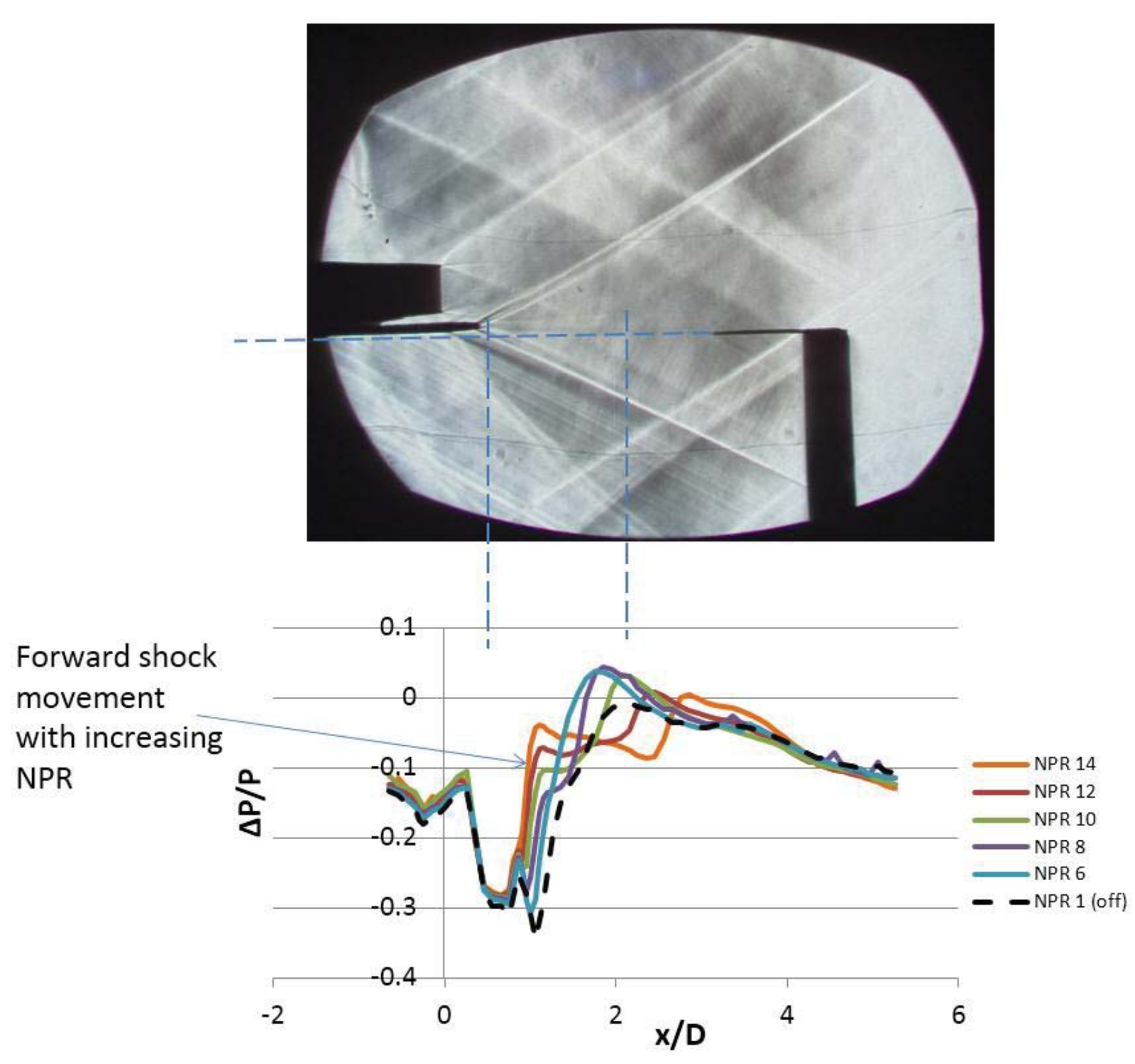

Figure 16. Schlieren image and lower static pressure profiles for the aft deck with $\mathrm{x} / \mathrm{D}=1.0$. 
Fig. 17 shows the schlieren image and the static pressure profiles as collected at one diameter above the nozzle centerline, displayed above the schlieren image (NPR=12). The shock at an $\mathrm{x} / \mathrm{D}=0.5$ is the lip shock, and moves upstream as NPR is increased. At $\mathrm{x} / \mathrm{D}>3$ the data shows a difference in the deck trailing edge shock location as NPR is increased from NPR=6 to NPR=14, the shock moves downstream with increasing NPR.

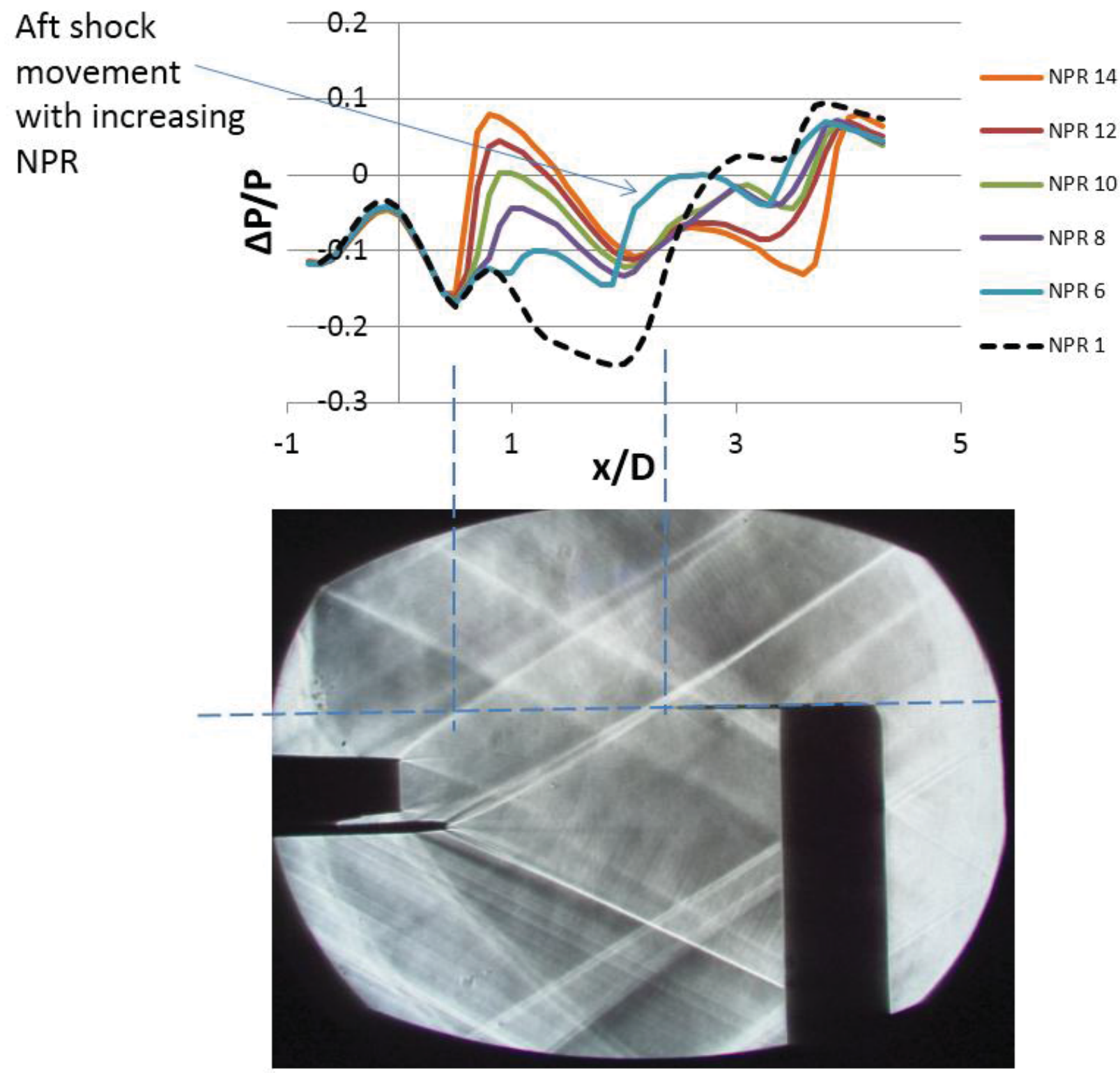

Figure 17. Schlieren image and upper static pressure profiles for the aft deck with $\mathrm{x} / \mathrm{D}=1.0$. 


\section{Summary and Conclusions}

An experiment was designed and conducted in the 1-foot by 1-foot Supersonic Wind Tunnel. The wind tunnel model consisted of a test nozzle supported by an upper plenum and strut. Instrumentation allowed calculation of NPR and measurement of near-field static pressure, presented as $\Delta \mathrm{P} / \mathrm{P}$. Schlieren images and flow visualization were used to validate proper placement of the model in the wind tunnel to avoid shock reflections and provide for a clean nozzle flow-field.

The experiment captured the leading edge shock and plume interaction with the long 2.5-degree and 5degree wedge configurations; and captured both the leading and trailing edge shocks with the short 5-degree wedge. Data and schlieren images demonstrated thickening of the wedge shock upon interaction with the shocks generated by the nozzle lip and the interaction with nozzle plume. The data also demonstrated approximately 0.5 in. of shock movement between nozzle pressure ratios of 6 to 14, which may translate into a large amount of shock movement on a full scale vehicle.

The experiment also captured the trailing edge shock and plume interaction with the aft deck configurations. Data and schlieren images demonstrated shock movement with nozzle pressure ratio for both the upper and lower deck shock waves. The upper shock waves moved downstream with increasing NPR, and the lower shock waves moved upstream with increasing NPR. These studies were conducted to provide insight into the effect of nozzle integration for full vehicle configurations; where the nozzle might be located under or over the trailing edge of a vehicle wing or tail. In this case, sensitivity to nozzle pressure ratio, or engine power setting, was demonstrated.

For a supersonic vehicle design with low sonic boom, the propulsion system cycle analysis would determine the engine NPR at cruise conditions. These experiments do not demonstrate an optimum operating condition, however they demonstrate that shock waves from the aft deck or tail move with increasing and decreasing NPR. For similar configurations, movement of the aircraft engine throttle setting may cause movement of aft shock waves and affect the sonic boom signature. Throttle movement may be necessary during aircraft acceleration, deceleration, and maneuvers. To verify the impact, a sonic boom analysis may be performed at reasonable offdesign throttle conditions. Results could be used to check if changes in NPR would result in significant shock movement and affect the sonic boom loudness.

\section{Acknowledgments}

This work was funded by the NASA Fundamental Aeronautics Program, High Speed Project.

\section{References}

${ }^{1}$ Graham, D., et al., “Aerodynamic Design of Shaped Sonic Boom Demonstration Aircraft,” AIAA 2005-0008, Jan. 2005.

${ }^{2}$ Freund, D., et al., "Quiet Spike Prototype Aerodynamic Characteristics From Flight Test,” AIAA 2008-125, Jan. 2008.

${ }^{3}$ Morgenstern, J., Buonanno, M., Norstrund, N., "N+2 Low Boom Wind Tunnel Model Design and Validation," AIAA-2012-3217, June 2012.

${ }^{4}$ Magee, T., Fugal, S., Fink, L., Shaw, S., "Boeing N+2 Supersonic Experimental Validation Phase II Program," AIAA-2014-2137, June 2014.

${ }^{5}$ Putnam, L. and Capone, F., "Experimental Determination of Equivalent Solid Bodies to Represent Jets Exhausting into a Mach 2.20 External Stream," NASA TN-D-5553.

${ }^{6}$ Barger, R. L. and Melson, N. D., "Comparison of Jet Plume Shape Predictions and Plume Influence on Sonic Boom Signature,” NASA TP-3172.

${ }^{7}$ Castner, R. S., "Exhaust Nozzle Plume Effects on Sonic Boom," Journal of Aircraft, 2012, vol. 49: 415-422, March-April 2012.

${ }^{8}$ Castner, R. S., "Slot Nozzle Effects for Reduced Sonic Boom on a Generic Supersonic Wing Section," AIAA2010-1386, Jan. 2010.

${ }^{9}$ Castner, R. S., "Analysis of Exhaust Plume Effects on Sonic Boom for a 59-Degree Wing Body Model," AIAA2011-917, Jan. 2011.

${ }^{10}$ Castner, R. S., "Exhaust Plume Effects on Sonic Boom for a Delta Wing and Swept Wing-Body Model," AIAA2012-1033, Jan. 2012. 
${ }^{11}$ Castner, R. S., Elmiligui, A., and Cliff, S. "Exhaust Nozzle Plume and Shock Wave Interaction,” AIAA-2013-12, Jan 2013.

${ }^{12}$ Castner, R.S., Zaman, K. Q., Fagan, A., and Heath, C., "Wedge Shock and Nozzle Exhaust Plume Interaction in a Supersonic Jet Flow," AIAA-2014-0232, Jan 2014.

13 Blevins, R. D., “Applied Fluid Dynamics Handbook,” Krieger, Florida, 1992 pp 126-135.

${ }^{14}$ Pinckney, S. Z., “A Short Static Pressure Probe Design for Supersonic Flow,” NASA TN D-7978. 